\title{
Poluição do ar e doenças respiratórias em Curitiba - PR
}

\author{
Sônia Maria Cipriano BAKONYI
}

Dissertação de Mestrado: Curso de Mestrado em Geografia - UFPR

Data da defesa: 04 abr. 2003

Banca:

Inês Moresco Danni-Oliveira (orientadora)

Alfésio Luis Ferreira Braga

Naldy Emerson Canali

\section{RESUMO}

A contaminação do ar nos grandes centros urbanos tem sido um grave problema no último século, merecendo, portanto, a atenção da comunidade científica e também da população, como uma fonte de possíveis agravos à saúde. Os efeitos da poluição do ar sobre a morbidade e também sobre a mortalidade têm sido observados nas mais diversas regiões do mundo. A faixa etária mais vulnerável é a das crianças e dos idosos, mesmo quando os níveis médios dos poluentes não são tão altos. Para que se pudessem identificar os possíveis efeitos dos poluentes do ar sobre a população infantil de Curitiba, realizou-se uma análise descritiva para o período de 1997 a 2000, e posteriormente um estudo de séries temporais para 1999 e 2000. Dados diários dos atendimentos ambulatoriais de 1997 a 2000 foram obtidos junto à Secretaria Municipal da Saúde (SMS). Os níveis diários do MPT, fumaça, $\mathrm{NO}_{2}$ e $\mathrm{O}_{3}$ foram obtidos junto ao IAP/Lactec e os dados referentes ao clima provieram do Inmet. Foi elaborado um estudo para o período total da distribuição têmporoespacial das doenças respiratórias e poluentes do ar para a cidade como um todo e ainda por regiões (mesoclimáticas), no qual se identificou a Região Nordeste da cidade como a portadora dos mais altos índices de poluição, bem como do mais elevado número de atendimentos por doenças respiratórias (DR). Para a série de 1999 a 2000 elaborou-se um estudo de séries temporais, no qual se definiu como variável dependente as DR, e como variáveis independentes os níveis médios diários dos poluentes, meses do ano, dias da semana, temperatura mínima e umidade relativa. Utilizouse a análise de correlação de Pearson e a de regressão de Poisson-GAM. Os poluentes MPT, fumaça e $\mathrm{NO}_{2}$ apresentaram associações estatisticamente significativas com as DR. Estas associações resistiram à inclusão das variáveis de controle, apresentando risco relativo à saúde. Diante da importância da poluição sobre a saúde infantil de Curitiba, no que diz respeito à morbidade, faz-se necessária a adoção de políticas públicas articuladas entre os diversos setores que gerenciam a vida urbana, para que se possa garantir a qualidade do ar curitibano, bem como a saúde de seus habitantes.

\section{Palavras-chave:}

Doenças, saúde, clima. 